\title{
CONTRIBUTION OF SHEEP MANURE BACTERIA IN THE IMMOBILIZATION OF ARSENIC FROM GROUNDWATER USING ZERO-VALENT
}

\author{
Wahyu Wilopo*1, Keiko Sasaki ${ }^{2}$, and Tsuyoshi Hirajima ${ }^{2}$ \\ ${ }^{1}$ Department of Geological Engineering, Gadjah Mada University, Indonesia \\ ${ }^{2}$ Department of Earth Resources Engineering, Kyushu University, Japan
}

\begin{abstract}
Permeable reactive barrier column tests were performed to investigate whether anaerobic bacteria in sheep manure could help remove As from groundwater. One column served as a control and was packed with zero-valent iron (ZVI), compost leaf, wood chips, glass beads, and gravel, after which it was sterilized. The other ('inoculated column') was packed with the same ingredients, with the addition of sheep manure as a source of anaerobic bacteria. Simulated As-contaminated groundwater was prepared based on groundwater samples from Sumbawa Island, Indonesia, but with the arsenic concentration adjusted to $50 \mathrm{mg} / \mathrm{L}$. The inoculated column was found to remove As more effectively from the simulated groundwater than the sterilized one. A gradual decrease in sulfate concentration was observed in the inoculated column at the rate of $0.26 \mathrm{mmol}$ of sulfate/L/day, suggesting that there was sulfate-reducing activity in the microbial population. In addition, the sulfur isotope ratio showed -4.3 $(\%)$ and $0.2(\%)$ in influent and effluent, respectively, indicating that sulfate-reducing bacteria (SRB) consumed $\delta^{32} S$ preferentially. Using population size estimates from the most probable number (MPN) method, the population of SRB was found to increase with distance traveled in the column. Profiling the community composition of the bacteria in different fractions of the inoculated column using polymerase chain reaction-denaturing gradient gel electrophoresis (PCR-DGGE) on $16 S$ rRNA sequences suggested that a majority of bacteria were various Clostridium species and one species of Proteobacteria, Geobacter metallireducens GS-15. Some of them may contribute to the removal of arsenic.
\end{abstract}

*Corresponding author: W. WILOPO, Department of Geological Engineering, Faculty of Engineering, Gadjah Mada University, Jl. Grafika 2 Yogyakarta, 55281, Indonesia. E-mail: wwilopo@gmail.com
Keywords: Sheep manure, zero valence iron, arsenic, immobilization, sulfate-reducing bacteria.

\section{Introduction}

In groundwater, the ratio of As (III) to As (V) can vary greatly as a result of variations in the abundance of redox-active solids, the activity of microorganisms, and the extent of convection and diffusion of $\mathrm{O}_{2}$ from the atmosphere. As expected from redox potentials, As (III) typically dominates in aquifers under strong reducing conditions (Smedley and Kinniburg, 2002). The more oxidized As (V) is more effectively removed by conventional treatment processes than As (III). Conventional oxidation methods may be costly and formation of harmful byproducts and sludge. Removing the different As species is important for lowering the amount of arsenic in drinking water to a level below the maximum concentration limit.

Current technologies for in situ treatment of groundwater to remove heavy metals involve the permeable reactive barrier (PRB). The PRB contains reactive materials and is placed underground in the path of the contaminated groundwater flow plume. Methods for removing heavy metals with a PRB include (1) sorption and precipitation, (2) chemical reaction, and (3) biologically mediated reactions (Scherer et al., 2000).

The biological approach to As removal is to use microorganisms that metabolically convert sulfate to sulfide under conditions favorable to growth (Dvorak et al., 1992). Bacteria have received significant attention as remediation tools for heavy metals and metalloids, because some can reduce metals by direct and indirect mechanisms. As scientists have gained a better understanding of how microorgan- 
isms interact with metals, they have developed lowcost, environmentally friendly technologies that use bacteria to remove heavy metal and radionuclide pollutants (Lloyd, 2003). For example, microbes can be used as a less expensive method for removing metals from contaminated groundwater (Cohen, 2006). Microorganisms need organic materials as a source of carbon, and well as other nutrients, and for developing an inexpensive biological remediation procedure, the organic material should be cheap, widely available, and highly effective. In this study, sheep manure was used as the source of anaerobic bacteria in the PRB. PCR-DGGE was used to investigate the bacterial species in the sheep manure that might help to remove As from groundwater.

\section{Experimental}

Material for the PRB consisted of ZVI and organic materials. ZVI is well known for immobilizing arsenic species. Connelly-GPM iron granules supplied by Connelly Ltd. (Chicago, Illinois, USA) were used. They had the following physical properties: a density between $2.24-2.56 \mathrm{~g} / \mathrm{cm}^{3}$, a mesh between 8-50, and a specific surface area of $2.407 \mathrm{~m}^{2} / \mathrm{g}$. Three organic materials were used in this experiment: sheep manure, compost leaf, and wood chips. These have been demonstrated to enhance SRB activity by 250$700 \%$ (Cohen, 2006). In addition, sheep manure has a low lignin content, a high degradability, and a capacity to stimulate bacterial activity (Gilbert $e t$ al., 2004). Sheep manure contains aerobic and anaerobic bacteria. The manure used in this study was taken from livestock in Mitsuse, Saga Prefecture, Japan, a few days before use. In order to maintain the permeability of the column, we mixed glass beads and gravel with the organic materials and ZVI.

Simulated groundwater was prepared based on the composition of As-contaminated groundwater found in Sumbawa, Indonesia. The As concentration used was 40 times higher than in actual groundwater to allow for an evaluation of PRB's ability to remove As quickly. The chemical composition of the influent groundwater was as follows (in g per liter of deionized water): $\mathrm{CaCO}_{3}(0.069), \mathrm{MgCO}_{3}(0.065)$, $\mathrm{KNO}_{3}(0.001), \mathrm{MnSO}_{4} \cdot 5 \mathrm{H}_{2} \mathrm{O}(0.263), \mathrm{KAsO}_{2}(0.058)$, $\mathrm{KH}_{2} \mathrm{AsO}_{4}(0.048)$, and $5 \mathrm{~mL} 1.2 \mathrm{M} \mathrm{HCl}$. The $\mathrm{pH}$ was adjusted to $6.25 \pm 0.25$ using $1 \mathrm{M} \mathrm{NaOH}$. The solution was purged with nitrogen gas for about 2 hours to minimize the content of dissolved oxygen, and stored under anaerobic conditions.

The two acrylic cylindrical columns used were 40 $\mathrm{cm}$ in height, $7.5 \mathrm{~cm}$ in inner diameter, and approximately $1767.86 \mathrm{~cm}^{3}$ in internal volume. The column materials consisted of 5\% (v/v) ZVI, 23\% (v/v) compost leaf, $22 \%(\mathrm{v} / \mathrm{v})$ sawdust, $30 \%(\mathrm{v} / \mathrm{v})$ glass beads, and $20 \%(\mathrm{v} / \mathrm{v})$ gravel. Column I was set up as the inoculated one, and column II as the sterilized one (control column). In the inoculated column, $2 \%(\mathrm{v} / \mathrm{v})$ of sawdust was replaced with sheep manure. All materials were sterilized by autoclaving, except for the sheep manure. Next, all materials were mixed homogeneously, poured evenly into the column, and purged with nitrogen gas to generate anaerobic conditions. To activate anaerobic microorganisms like SRB in the inoculated column, $1.5 \mathrm{~L}$ of $6 \mathrm{M}$ sodium lactate was introduced. The porosity of the inoculated and sterilized columns after packing was $37.37 \%$ and $36.20 \%$, respectively. The flow rate of influent was initially set at $0.21 \mathrm{~cm} / \mathrm{h}$ from the bottom to the top by peristaltic pumps, resulting in 2.77 days of average residence time [1 pore volume (pv)]. The column was monitored regularly. All experiments were conducted in an anaerobic glove box (COY, USA) purged with a $95 \% \mathrm{~N}_{2}: 5 \% \mathrm{H}_{2}$ gas mixture.

Temperature, $\mathrm{pH}$, redox potential, and alkalinity were measured immediately after collection of the effluent. Determination of As species and concentrations was done using atomic adsorption spectrometry (AAS, Shimadzu, Japan). Anions and cations were determined using Dionex DX-120 ion chromatography (IC). Total organic carbon (TOC) was measured using a TOC analyzer from Shimadzu. Elements precipitated on ZVI at the end of the column run was analyzed using $X$-ray fluorescence (XRF; RIX-3100, Rigaku).

The most probable number (MPN) method was used to determine the number of sulfate-reducing bacteria (SRB) in solid samples of PRB. Four samples (S1, S3, S7, and S10) were collected from PRB materials at different heights in the inoculated column. MPN medium solution (2 L) contained the following components (in grams per 2 liters): $\mathrm{KH}_{2} \mathrm{PO}_{4}$ (0.5), $\mathrm{NH}_{4} \mathrm{Cl}(1), \mathrm{Na}_{2} \mathrm{SO}_{4}$ (4.5), $\mathrm{CaCl}_{2} \cdot 2 \mathrm{H}_{2} \mathrm{O}(0.4)$, $\mathrm{MgSO}_{4} \cdot 7 \mathrm{H}_{2} \mathrm{O}(0.06)$, Na-lactate (2.502), Na-acetate (1.28), yeast extract (1.0), and Na-citrate (0.3). All reagents were dissolved in neutral $\mathrm{pH}$ were dissolved in neutral $\mathrm{pH}$ to avoid $\mathrm{CaSO}_{4}$ precipitation. One gram of solid sample from each fraction and one iron nail were transferred to anaerobic culture tubes containing $9 \mathrm{ml}$ of MPN medium. Iron nails supply Fe (II) ions in the medium. After an incubation of 4 weeks in an anaerobic box, the number of culture bottles containing blackish, precipitated iron sulfides was used to calculate the SRB population. DNA was extracted from solid and liquid samples of the column using a DNA isolation kit from MO BIO Laboratories Inc The extraction procedure was performed according to the manufacturer's instructions. Extracted DNA was first amplified by polymerase chain reaction (PCR), then 
subjected to denaturing gradient gel electrophoresis. The primers used for PCR are presented in Table 1. PCR amplification was performed in a total of $50 \mu \mathrm{L}$. Each PCR mixture contained $5 \mu \mathrm{L}$ template DNA, $25 \mu \mathrm{L}$ Premix TaqTM reaction buffer, 1 $\mu \mathrm{M}$ forward primer, $1 \mu \mathrm{M}$ reverse primer, and $18 \mu \mathrm{L}$ sterilized water. The premix Taq buffer and primers were purchased from Takara Bio Inc. (Japan). Thermal cycling was carried out with an initial denaturation step of $94{ }^{\circ} \mathrm{C}$ for $10 \mathrm{~min}$, followed by $30 \mathrm{cy}$ cles of denaturation at $94{ }^{\circ} \mathrm{C}$ for 1 minute, annealing at $52{ }^{\circ} \mathrm{C}$ for 2 minutes, and elongation at $72{ }^{\circ} \mathrm{C}$ for 2 minutes. The integrity of the total DNA was checked by agarose gel electrophoresis and ethidium bromide staining, and DNA concentration was estimated using molecular weight standards (Low DNA Mass Ladder, BIONEER). PCR products showing the correct molecular weight and sufficiently high concentration were subsequently analyzed by DGGE as described by Muyzer et al (1993). The PCR products were applied to an $8 \%(\mathrm{w} / \mathrm{v})$ polyacrylamide gel containing a linear gradient ranging from $30 \%$ to $70 \%$ of denaturant (7 M urea and $40 \%$ formamide). Gel electrophoresis was performed for $16 \mathrm{~h}$ at $175 \mathrm{~V}$ in $1 \mathrm{X}$ TAE buffer $(0.04 \mathrm{M}$ Trisacetate, $1 \mathrm{mM}$ EDTA, $\mathrm{pH} 8.5)$ at a constant temperature of $60{ }^{\circ} \mathrm{C}$. After the electrophoresis, the gel was stained with ethidium bromide solution and photographed with a Fluor-S Multilmager (Bio-Rad). To determine the gene sequences corresponding to the DGGE bands, the bands from the DGGE fingerprints were cloned and sequenced. A second DGGE was necessary to confirm that the band from the first DGGE contained a single species of DNA. Excised bands were dissolved in $50 \mu \mathrm{L}$ of deionized $\mathrm{H}_{2} \mathrm{O}$ and shaken overnight at room temperature. Then the dissolved DNA was amplified again by PCR using primers $341 \mathrm{~F}$ and $518 \mathrm{R}$. The PCR products were reconcentrated using $3 \mathrm{M}$ sodium acetate and ethanol (99.5\% and 70\%). The concentrated DNA was purified using the Qiaex II gel extraction kit (Qiagen). Pure DNA was examined by PCR for the presence of the appropriate insert using the $341 \mathrm{~F}$ or $518 \mathrm{R}$ primer. DNA containing the inserts was cloned, and inserts showing different DGGE patterns were sequenced using the CEQtm 8000 Genetic Analyzer (Beckman Coulter). Clone sequences were entered into the program BLASTN 2.2.4 (Basic Logical Alignment Tool, http://www.ncbi.nlm.nih.gov/BLAST/) to identify similar sequences in known bacterial genomes.

\section{Results and discussion}

Changes in $\mathrm{pH}$, Eh, alkalinity, temperature, total organic carbon (TOC), and concentration of $\mathrm{SO}_{4}^{2-}$ over the course of the experiments are presented in Fig- ure 1. Initially, $\mathrm{pH}$ increased in both columns from 6.25 in the influent to around 7 in the effluent, then decreased after $\mathrm{pv} \approx 33$. Dissolving of the ZVI and, in the inoculated column, dissolving of the sheep manure caused a $\mathrm{pH}$ increase in both columns until $\mathrm{pv} \approx 7$. Eh decreased in both columns throughout the experiment, indicating that reduction occurred. Effluent alkalinity was higher in the inoculated column than the sterilized one, but after $\mathrm{pv} \approx 25$, these values suddenly decreased to become nearly equal to that of the influent. The alkalinity decrease was probably caused by a decrease in the amount of bicarbonate, which was produced by SRB respiration of organic carbon:

$$
\begin{gathered}
\mathrm{SO}_{4}^{2-}+2 \mathrm{CH}_{2} \mathrm{O} \rightarrow \mathrm{H}_{2} \mathrm{~S}+2 \mathrm{HCO}^{3-} \\
\mathrm{H}_{2} \mathrm{~S}+\mathrm{M} \rightarrow \mathrm{MS}(\mathrm{s})+2 \mathrm{H}^{+}(\mathrm{M} \text { is a metal })
\end{gathered}
$$

The formation of bicarbonate indicates the ability of SRB to control the alkalinity and $\mathrm{pH}$ in the column (Figures 1a and 1c). The temperature of groundwater inside the columns fell slightly during the experiment, as shown in Figure $1 d$. TOC was higher in the inoculated column than in the sterilized one until pv $\approx 25$, after which the values were similar (Figure 1e).

Figure 1f shows the variation in sulfate concentration over time. Sulfate concentration in the effluent of the inoculated column suddenly decreased after $\mathrm{pv} \approx 2.5$, whereas it remained relatively stable in the sterilized column. The rate of decrease in sulfate concentration was greatest at $\mathrm{pv} \approx 12$, where the difference from the initial value was $36 \mathrm{mg} / \mathrm{L}$. The maximum rate of sulfate reduction was calculated to be $0.26 \mathrm{mmol} / \mathrm{L} /$ day. Sulfate concentration in the inoculated column decreased because of SRB activity. In addition, the sulfur isotope ratio from the solution samples at $\mathrm{pv} \approx 36$ showed that $\delta^{34} \mathrm{~S}$ were $-4.3(\%)$ and $+0.2(\%)$ in the influent and effluent of the inoculated column, respectively. The effluent of the sterilized column was relatively stable $(-3.9(\%))$ compared with influent. SRB prefers to consume light sulfate $\left(\delta^{32} S\right)$, resulting in a relative increase of $\delta^{34} S$ (Detmers et al., 2001). Therefore, the observed sulfate reduction and increase in the $\delta^{34} \mathrm{~S}$ value in the effluent of the inoculated column indicated the presence of SRB. Sulfate reduction became inefficient after $\mathrm{pv} \approx 25$ because of an increase in As concentration in the inoculated column, and because nutrient supply could not keep up with metabolic demand, leading to a reduction in TOC.

Figure 2 shows arsenic removal over time in both columns. Arsenic removal in the inoculated column was more effective than in the sterilized one. The mechanism of As removal was mainly adsorption or co-precipitation with ZVI (Bang et al., 2005; 
Table 1: Primers used for PCR amplification in this study

\begin{tabular}{llll}
\hline \multicolumn{1}{c}{ Primer } & \multicolumn{1}{c}{ Sequence $\left(5^{\prime}-3^{\prime}\right)$} & \multicolumn{1}{c}{ Target } & \multicolumn{1}{c}{ Reference } \\
27F & AGAGTTTGATCCTGGCTCAG & Bacterial 16S rDNA & Edwards et al. (1989) \\
1523R & AAAGGAGGTGATCCAGCC & Bacterial 16S rDNA & Edwards et al. (1993) \\
341F & CCTACGGGAGGCAGCAG & Bacterial 16S rDNA & Muyzer et al. (1993) \\
534R & ATT ACC GCG GCT GCTGG & Bacterial 16S rDNA & Neefsr et al. (1990) \\
341F-GC & CGCCCGCCGCGCGCGGCGGGCGGGGCGGG & Bacterial 16S rDNA & Muyzer et al. (1993) \\
& GGCACGGGGGGCCTACGGGAGGCAGCAG & & \\
\hline
\end{tabular}
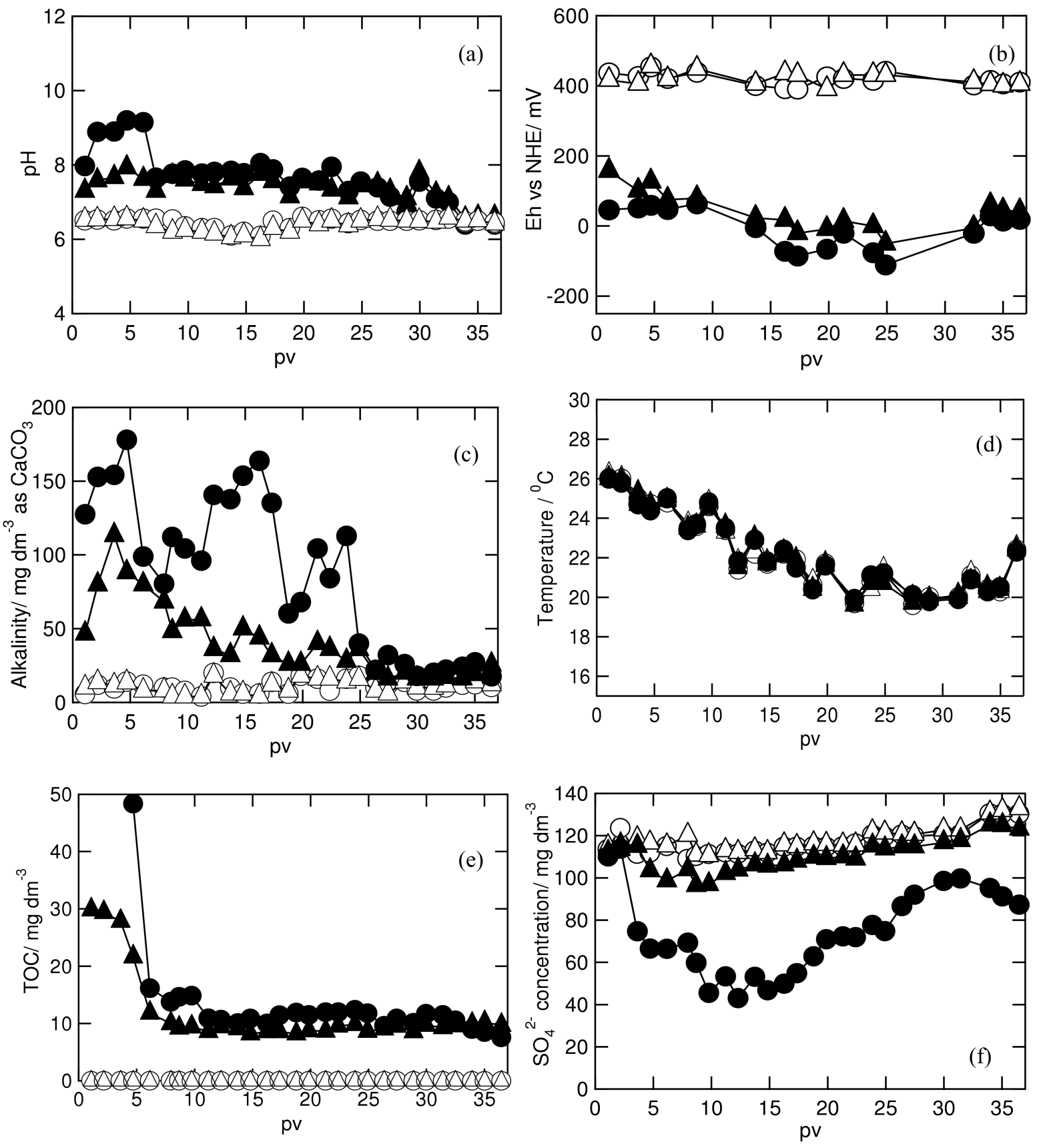

Figure 1: Changes in $\mathrm{pH}$, Eh, alkalinity, temperature, TOC, and sulfate levels in the influent and effluent of each column over time. Open triangle: influent sterilized column; open circle: influent inoculated column; closed triangle: effluent sterilized column; closed circle: effluent inoculated column. 


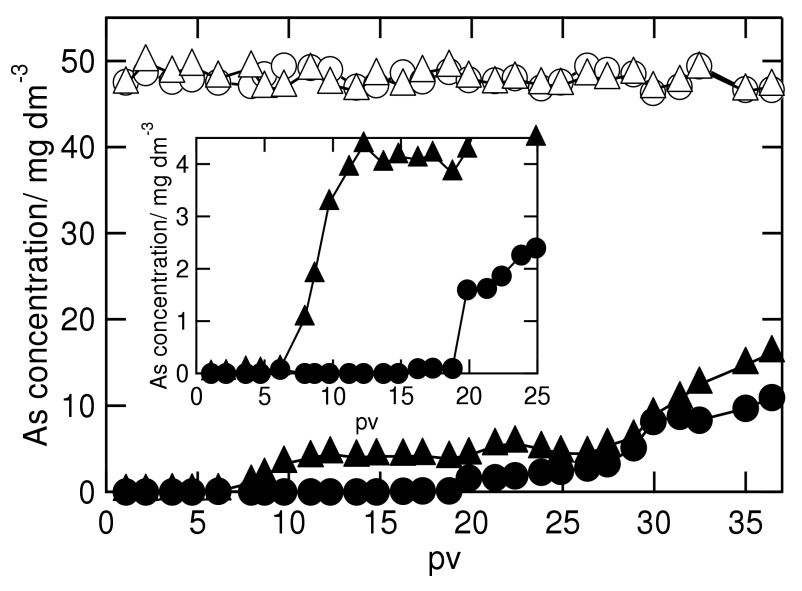

Figure 2: Arsenic removal versus time in each column. Symbols are the same as in Figure 1.

Lien and Wilkin, 2003). The difference in As removal efficiency between the inoculated and sterilized columns was most likely caused by SRB activity. The hydrogen sulfide created during the reduction reaction of SRB will react with metals, forming insoluble metal sulfide precipitates. This is most likely what happened to the As in the groundwater influent in the inoculated column.

After $\mathrm{pv} \approx 25$, both columns became less efficient at removing As because of decreases in iron capacity and, in the inoculated column, SRB activity as well. The increase of arsenic in the column is thought to be the main factor inhibiting SRB growth in the inoculated column. Quan et al. (2004) reported that the consumption of sulfate by SRB significantly decreased with an increase in cyanide concentration from $1 \mathrm{mM}$ to $2 \mathrm{mM}$. On the contrary, Sani et al. (2001) reported an IC50 of $1.02 \mathrm{mg} / \mathrm{L}$ for $\mathrm{Cu}$ (II), though their experiments used a single SRB strain and a metal toxicity medium containing constituents that did not result in any abiotic precipitation of metal ions. These studies suggest that SRB activity is strongly influenced by the composition of the mobile phase of the column.

The total amount of arsenic removed was calculated for each column by integrating the areas of the breakthrough curves of the effluent (Figure 2), dividing by the upper areas of the breakthrough curves of the influent, and multiplying the result by the total As in the influent during the experiment. The total As precipitated in the inoculated and sterilized columns was $1314.496 \mathrm{mg}$ and $1182.244 \mathrm{mg}$, respectively. The arsenic removal capacity of iron in each column was determined by taking the net amount of arsenic removed and dividing it by the ZVI mass. Using this method, the arsenic removal capacity in the inoculated and sterilized columns was calcu- lated to be $5.953 \mathrm{mg}$.As/g-ZVI and $5.354 \mathrm{mg}$.As/gZVI, respectively. These values were lower than the $7.5 \mathrm{mg}$.As/g-ZVI reported by Lien and Wilkin (2003), whose column material consisted entirely of ZVI. The lower As-binding capacity of ZVI in this study was probably due to the presence of organic carbon. Grafe et al. (2001) reported that dissolved organic carbon can reduce adsorption of As (V) on geothite by $17-27 \%$. Thus, the removal of As in the inoculated column was probably linked to the sulfate reduction due to SRB activity. Therefore the differences in the As-binding capacity of ZVI in the two columns was most likely caused by SRB activity in the inoculated column. This may reflect either the precipitation of As as arsenic sulfides, such as $\mathrm{As}_{2} \mathrm{~S}_{3}$, or the incorporation of As into Mn- and Fe-sulfides, followed by redissolving or desorption of the As to form soluble thioarsenite (As(III)) complexes. Castro et al. (1999) reported this behavior in SRB fed with organic wastes and used to treat contaminated water in an open pit mine.

The vertical profile of sulfate and As at $\mathrm{pv} \approx 36$ is illustrated in Figure 3. The greatest decrease in the concentration of As and sulfate occurred in the upper part of the column, further supporting the notion that both processes are the result of SRB activity. The decrease in sulfate concentration in the inoculated column was recognized when the concentrations were samples along the entire length of the column. The sulfate concentration in the sterilized column, by contrast, was relatively stable. Together, these results indicate that the inoculated column removed As more effectively than the sterilized one, and that the more efficient removal was linked to SRB activity, which also reduced sulfate in the applied sample.

Figure 4 shows As speciation in both columns. The concentration of As (III) in the effluent of both columns was similar, though the inoculated column showed a lower level than the sterilized one. The inoculated column removed essentially all of the As $(\mathrm{V})$ by $\mathrm{pv} \approx 15$. In the case of the sterilized column, however, As (V) was still detectable in the effluent from the start of the experiment.

Figure 5 shows XRF analyses of ZVI samples taken at different column heights in both columns after As was allowed to accumulate. At all column heights tested, the sulfur concentration was higher in the inoculated column than the sterilized one. The arsenic concentration at the bottom of the sterilized column was higher than at the bottom of the inoculated one, and the concentration in the latter column increased with increasing distance from the point of sample loading. The XRF results were consistent with the effluent analysis. 

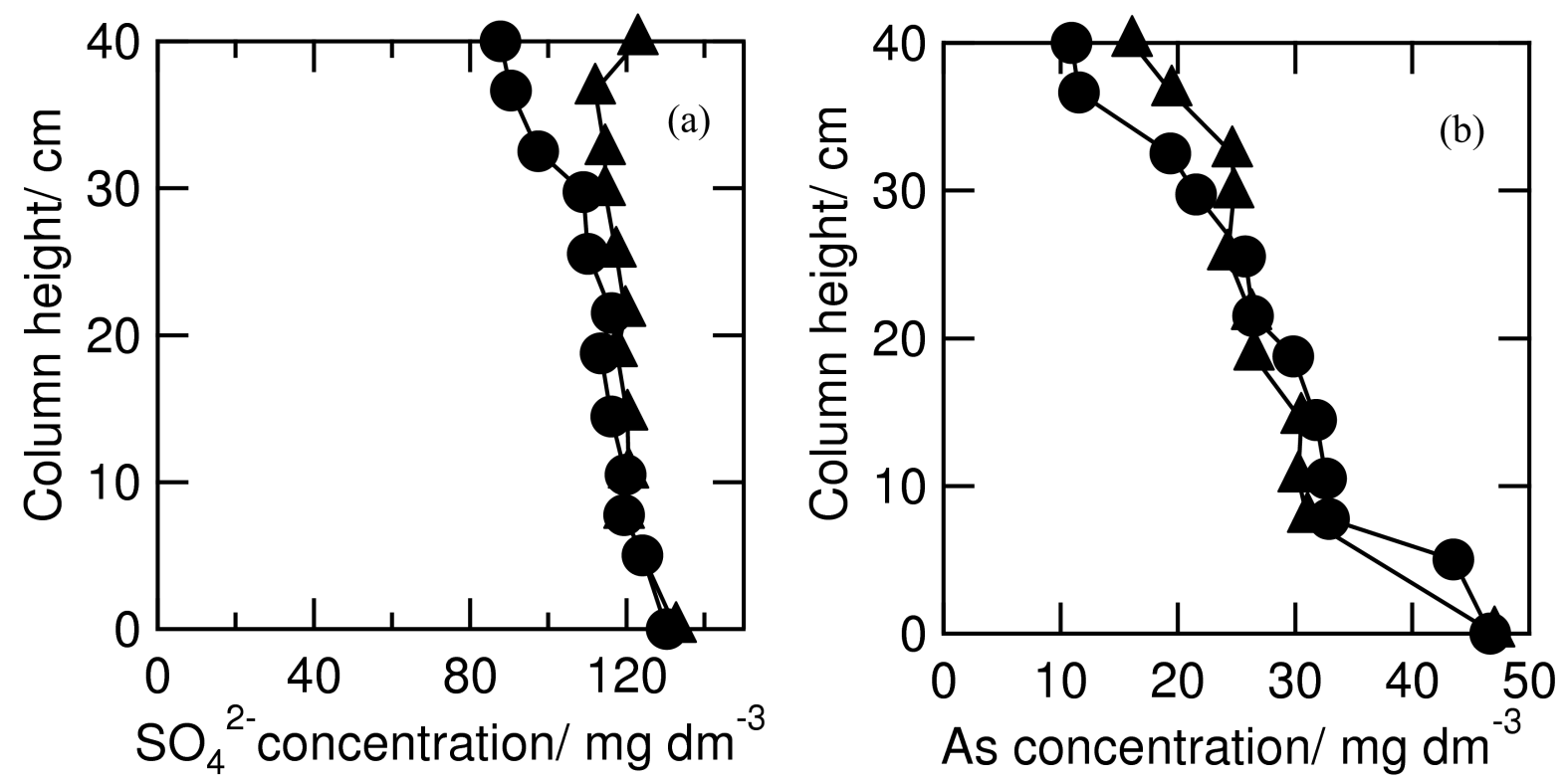

Figure 3: Vertical profiles of $\mathrm{SO}_{4}^{2-}(\mathrm{a})$ and $\mathrm{As}(\mathrm{b})$ at $\mathrm{pv} \approx 36$. Closed triangle: effluent in the sterilized column and closed circle: effluent in the inoculated column

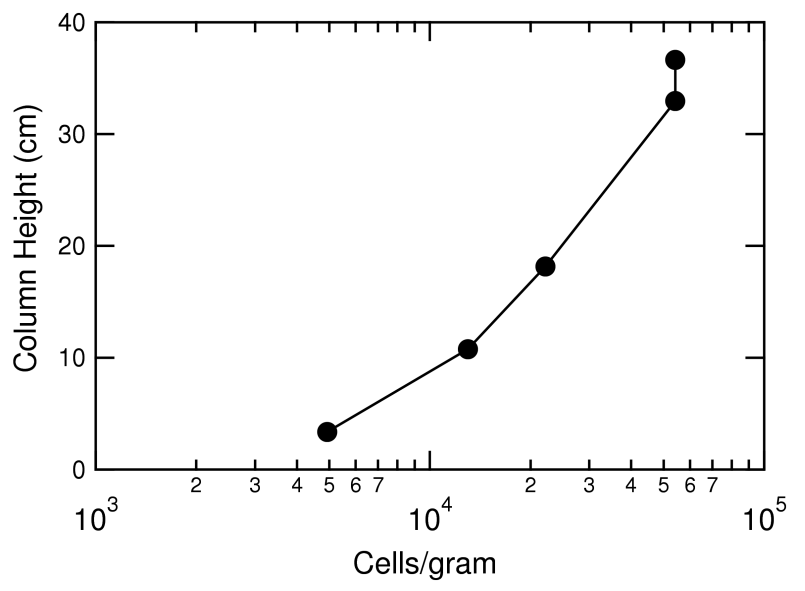

Figure 6: Concentration of SRB versus column height in the inoculated column.

Figure 6 shows the vertical profile of the SRB population at $\mathrm{pv} \approx 36$. The MPN modeling showed that the population varied from $5 \times 104$ cells/gram at the bottom part of the column to $6 \times 105$ cells/gram at the top of the column. The MPN result is consistent with the idea that SRB growth caused decreases in the As and sulfate concentrations (Figures $3 \mathrm{a}$ and $3 \mathrm{~b})$. The larger population of SRB in the upper part of the inoculated column caused a decrease in sulfate and more efficient As removal.

To identify the subpopulations within the SRB, DNA analysis was conducted on liquid and solid samples from the inoculated column. Each sample was divided into 10 fractions. Details of the samples are presented in Table 2. The results of PCRDGGE to identify bacterial subpopulations is presented in Figure 6. Sequences were determined from 36 bands, and BLAST comparisons with known bacterial sequences revealed that six major species contributed to As removal. The length of the sequences used to calculate each similarity value is shown in Table 3 as an indication of the quality of the species match. The most intense bands in the profiles obtained with both primers sets corresponded to Clostridium kluyveri DSM 555 (band 1), Geobacter metallireducens GS-15 (band 2), Anaerostipes caccae DSM 14662 (band 3), Desulfitobacterium hafniense Y51 (band 4), Clostridium sp. OhILAs (band 5), and Clostridium difficile 630 (band 6).

Bands with sequences of Geobacter metallireducens GS-15, Anaerostipes caccae DSM 14662, and Clostridium difficile 630 were detected in almost all samples from solid and liquid. Thus these bacteria can tolerate high concentrations of As. In contrast, bands with sequences from Clostridium kluyveri DSM 555, Desulfitobacterium hafniense Y-51, and Clostridium sp. OhILAs were found in solid and liquid samples exclusively from the upper part of the inoculated column (S1 and L1). This suggests that those bacteria can not survive under high concentrations of arsenic, because the upper part of the inoculated column has the lowest As concentration (Figure $3 b$ ).

Based on the characteristics of the species identified in the SRB, we believe that a few are responsible for the decrease in sulfate and As (V) concentra- 

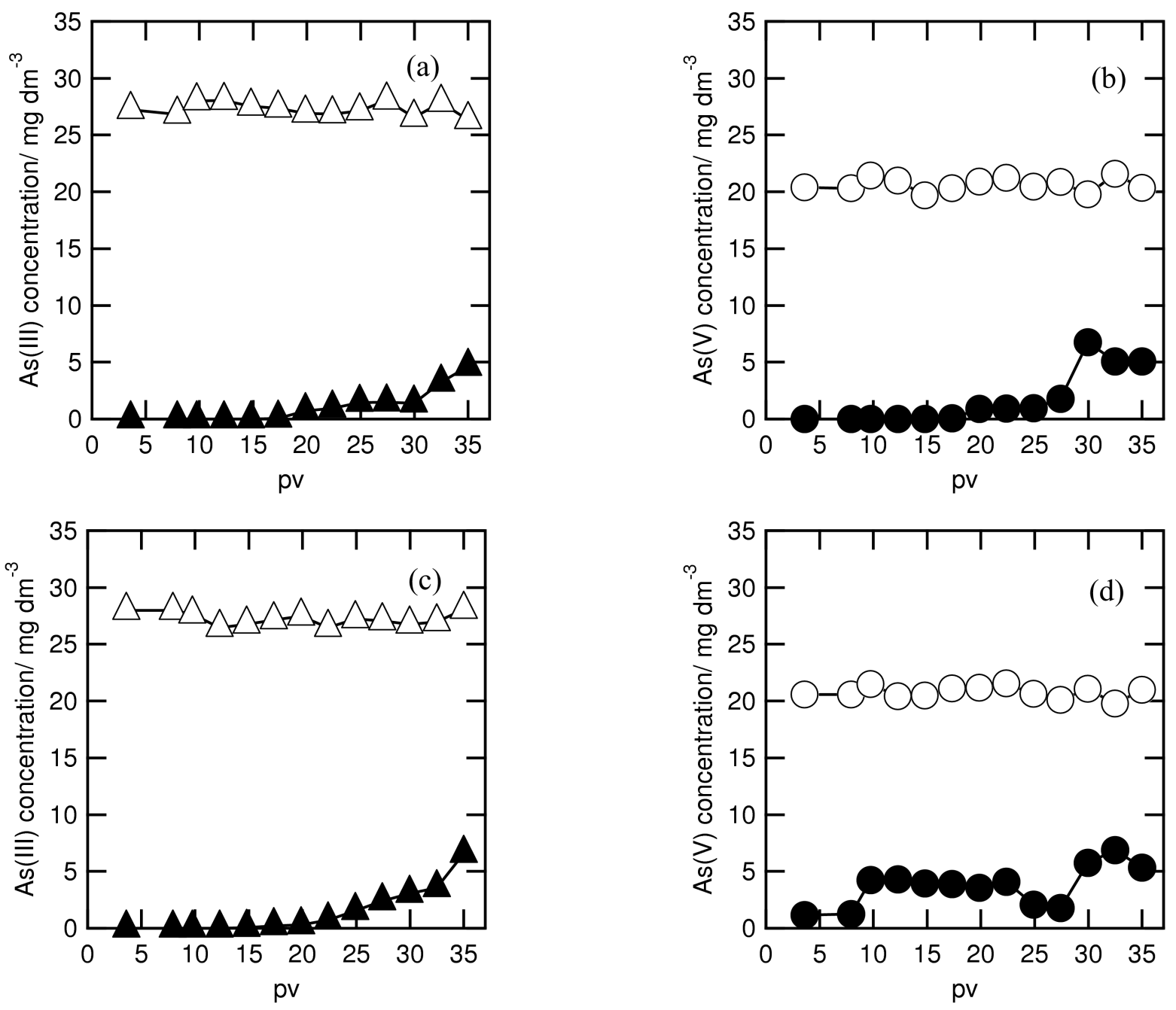

Figure 4: Levels of different arsenic species over time in each column. a-b are for the inoculated column; c-d are for the sterilized column. Closed triangle: influent As (III); closed circle: influent As (V); open triangle: effluent As (III); open circle: effluent As (V).
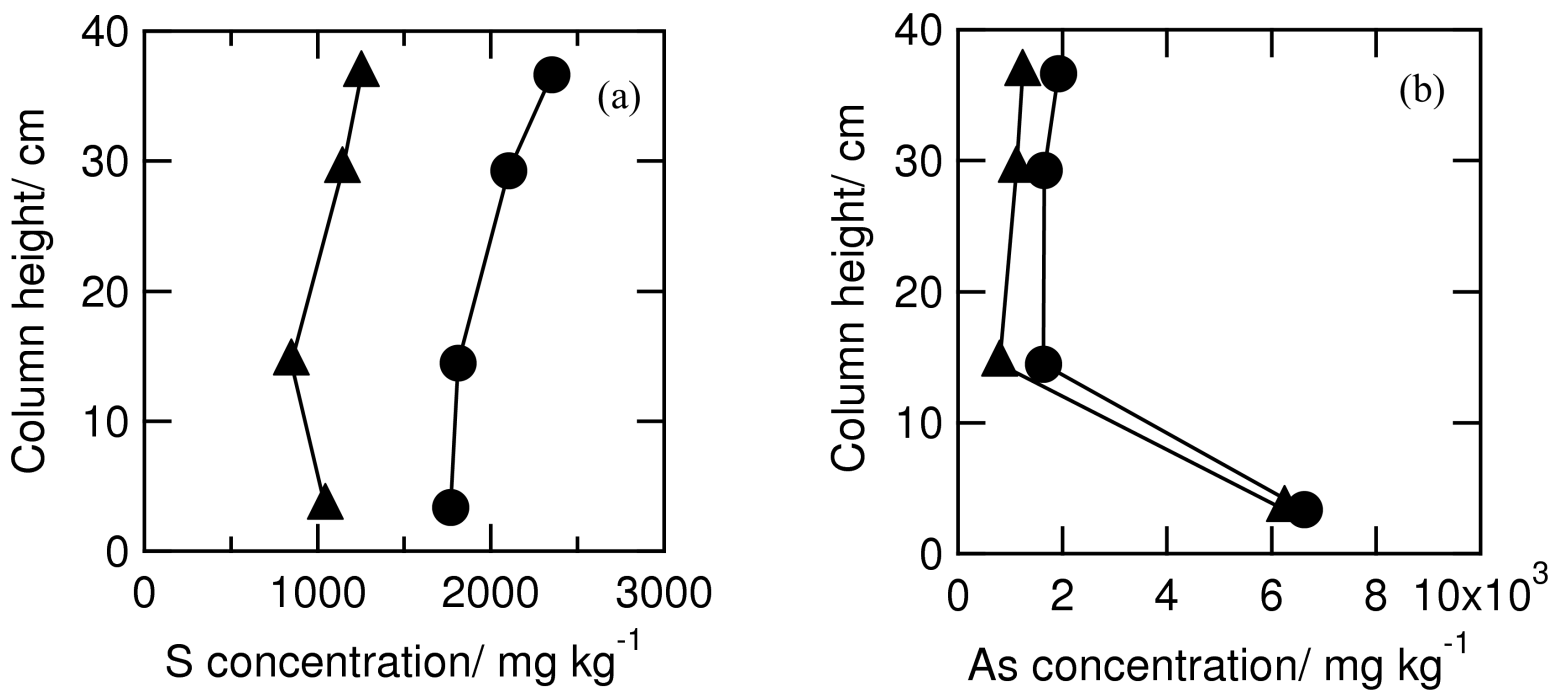

Figure 5: XRF data from ZVI samples at different column heights at $\mathrm{pv} \approx 36$. 
WILOPO et al.

Table 2: Solid and liquid sample positions

\begin{tabular}{cccc}
\hline Sample & Sample position at column $(\mathrm{cm})$ & Solid sample ID & Liquid sample ID \\
\hline 1 & $34.8-38.5$ & S1 & L1 \\
2 & $31.1-34.5$ & S2 & L2 \\
3 & $27.4-31.1$ & S3 & L3 \\
4 & $23.7-27.4$ & S4 & L4 \\
5 & $20.0-23.7$ & S5 & L5 \\
6 & $16.3-20.0$ & S6 & L6 \\
7 & $12.6-16.3$ & S7 & L7 \\
8 & $8.9-12.6$ & S8 & L8 \\
9 & $5.2-8.9$ & S9 & L9 \\
10 & $1.5-5.2$ & S10 & L10 \\
\hline
\end{tabular}

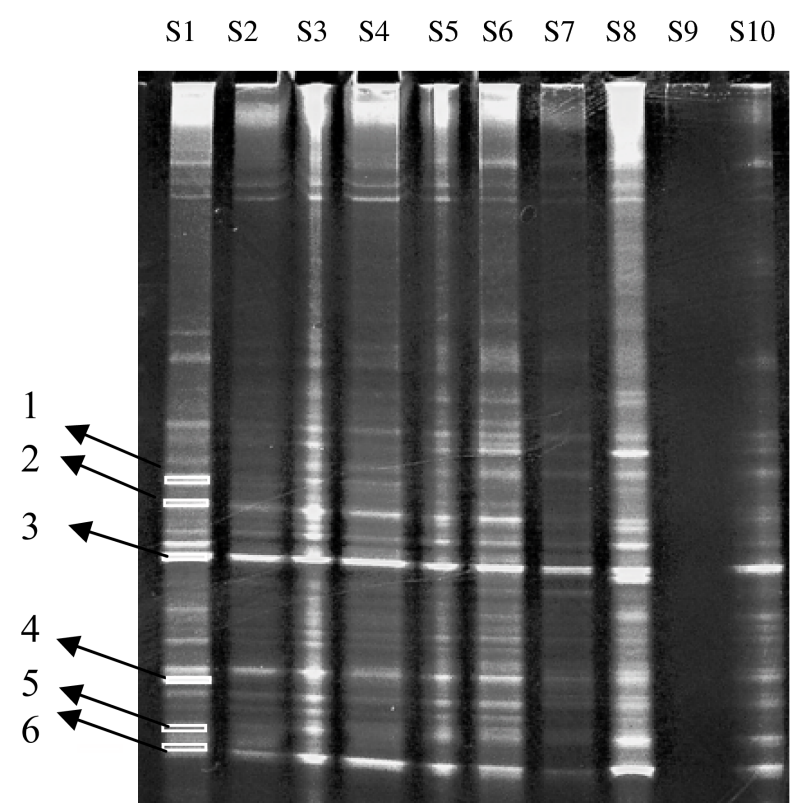

L1 $\quad$ L2 $\quad$ L3 $\quad$ L4 $\quad$ L5 $\quad$ L6 L7 $\quad$ L8 $\quad$ L9 $\quad$ L10

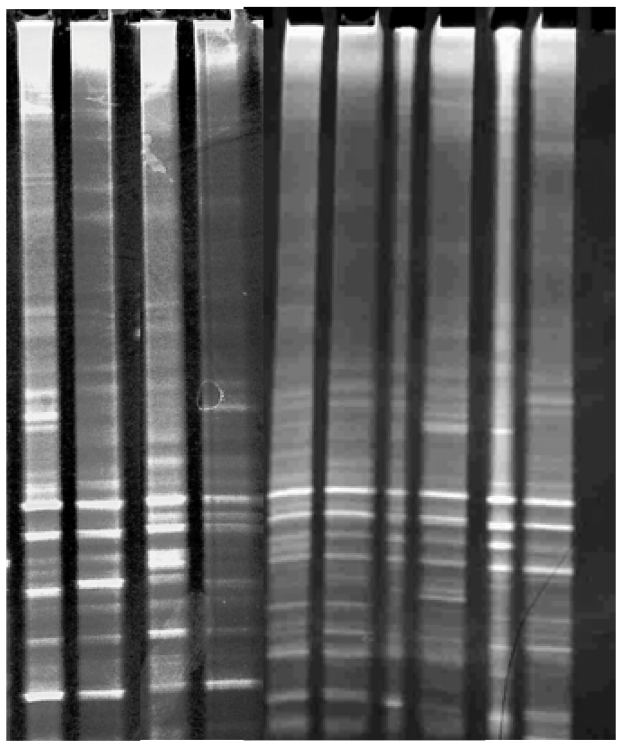

Figure 7: DGGE fingerprints of bacteria obtained from solid and liquid samples at $\mathrm{pv}=36$. The numbers on the left side of the gel indicate S1 bands that were sequenced. 


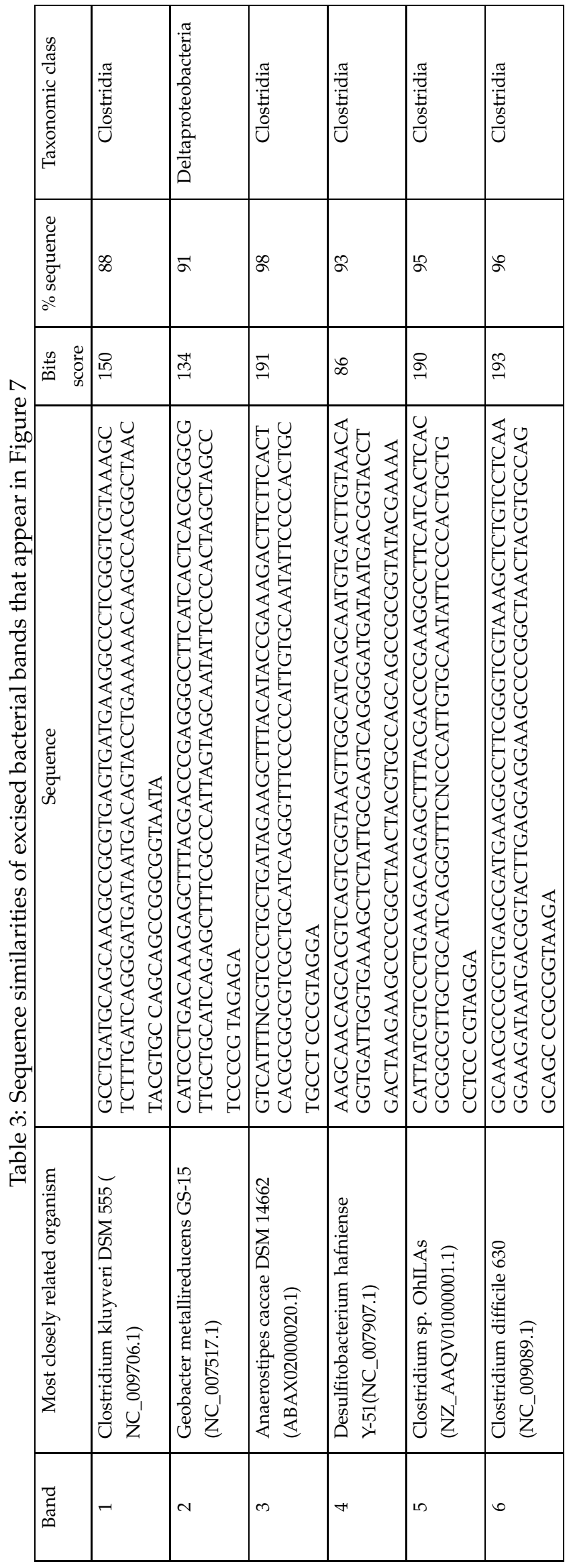

tion. One of the responsible species is likely to be Desulfitobacterium hafniense Y-51. The genus Desulfitobacterium was originally described as a taxon containing organisms that reduce elemental sulfur and sulfite but not sulfate (Utkin et al., 1994). Desulfitobacterium hafniense $Y-51$, however, has been reported capable of reducing sulfate (Suyama et al., 2001). This bacterial species uses both pyruvate and lactate as electron donors, and it can use metal ions as electron acceptors. It can also grow and reduce As (V) using lactate as the electron donor (Nonaka et al., 2005). In addition, Clostridium sp. OhILAs also respires arsenate and thiosulfate (Stolz et al., 2006). Clostridium sp. OhILAs can tolerate high arsenate concentrations $(>40 \mathrm{mM})$ and they readily degrade the organoarsenical 3-nitro-4-hydroxy benzene arsonic acid (roxarsone) within 48 hours (Stolz et al., 2007). In addition to the Clostridia class, Geobacter metallireducens GS-15, which is grouped among delta proteobacteria, can convert sulfate to sulfide. The Geobacter genus is able to colonize habitats with elevated metal concentrations. The analysis of the $16 \mathrm{~S}$ rRNA sequence of Geobacter metallireducens indicates that its closest known relatives are Gram-negative reducers of sulfur and sulfate. It is the first organism known to oxidize organic compounds completely via the reduction of iron and other metals (Lovely et al., 1993). Geobacter metallireducens expresses flagella and pili only when grown on insoluble Fe (III) and Mn (IV) oxide, and is chemotactic towards Fe (II) and Mn (II) under these conditions (Childers et al., 2002).

\section{Conclusions}

The use of sheep manure significantly improves the efficiency of a PRB to remove As from contaminated groundwater. Arsenic was removed effectively by being immobilized in the ZVI and by being incorporated into precipitates that formed because of bacterial consumption of sulfate. The bacterial species in the PRB were identified by PCRDGGE on solid and liquid samples after the PRB had been allowed to accumuluate As. The observed reduction in sulfate concentration and increase in $\delta^{34} S$ was probably caused by the SRB species Desulfitobacterium hafniense Y-51 and Clostridium sp. OhILAs. The iron-reducing bacterium Geobacter metallireducens was also detected. All of these species contributed to remove As from the contaminated sample. Clostridium sp. OhILAs and Geobacter metallireducens were more resistant than Desulfitobacterium hafniense $Y-51$ to the high concentration of As in the sample. PRBs with and without sheep manure did not remove As effectively after $\mathrm{pv} \approx 25$, and this was due mainly to a decrease in ZVI capacity, and 
in the case of the PRB with manure, to a reduction of bacterial activity. The bacterial activity probably fell because of increasing toxicity in the column and because of nutrient shortages. The results from this experiment suggest that sheep manure can be used as a good alternative PRB material for the biological remediation of samples contaminated with As.

\section{Acknowledgments}

Financial support was provided by Japan Society for the Promotion of Sciences (JSPS 19656239). The authors would like to thank Dr. Toshiro Yamanaka at Hiroshima University for sulfur isotopic analysis.

\section{References}

Altschul, S.F., Madden, T.L., Schäffer, A.A., Zhang, J., Zhang, Z., Miller, W. \& Lipman, D.J. (1997) "Gapped BLAST and PSI-BLAST: a new generation of protein database search programs" Nucleic Acids Res. 25: 33893402.

Bader, J. , Giinther, H. , Schleicher, E. , Simon, H. , Pohl, S. , and Mannheim, W. (1980) Utilization of (E)-2butenoate (Crotonate) by Clostridium kluyveri and some other Clostridium species. Archives of Microbiology 125: 159-165.

Bang S., G.P.Korfiatis, X. Meng (2005) Removal of Arsenic from Water by Zero-valent Iron. Journal of Hazardous Materials 121: 61-67.

Castro, J. M., Wielinga, B. W., Gannon ,J. E. and Moore, J. N. (1999) Stimulation of Sulfate-Reducing Bacteria in Lake Water from a Former Open-Pit Mine Through Addition of Organic Wastes. Water Environment Research 71: 218-223.

Childers, S. E., Ciufo, S., Lovley, D. R. (2002) Geobacter metallireducens Accesses Insoluble Fe(III) Oxide by Chemotaxis. Nature 416: 767-768.

Cohen R.H. (2006) Use of Microbes for Cost Reduction of Metal Removal from Metals and Mining Industry Waste Streams. Journal of Cleaner Production 14: 1146-1157.

Detmers, J., Chert, V. B., Habicht, K. S. , and Kuever, J. (2001) Diversity of Sulfur Isotope Fractionations by Sulfate-Reducing Prokaryotes. Applied and Environmental Microbiology 67: 888-894.

Dvorak D.H., Hedin R.S., Edenborn H.M., McIntire P.E. (1992) Treatment Of Metal-Contaminated Water Using Bacterial Sulfate Reduction: Results from Pilot-Scale Reactors. Biotechnology and Bioengineering 40: 609-616.

Edwards, U., Rogall, T., Blocker, H., Emde, M. and Bottger, E.C.: Nucleic Acids Research 17: 7843-7853.

Gilbert, O., J. de Pablo, J.L. Cortina, and C. Ayora (2004) Chemical Characterization of Natural Organic Substrates for Biological Mitigation of Acid Mine Drainage. Water Research 38(19): 4186-4196.

Grafe, M. , Eick, M. J. and Grossl, P. R. (2001) Adsorption of Arsenate (V) and Arsenite (III) on Goethite in the Presence and Absence of Dissolved Organic Carbon. Soil Science Society of America Journal. 65: 1680-1687.
Lien, H. L. and Wilkin, R. T. (2003) High-level Arsenite Removal from Groundwater by Zero-valent Iron. Chemosphere 53: 715-725.

Lloyd, J.R. (2003) Microbial Metal Reduction. FEMS Microbiology Reviews 27: 411-425.

Lovley, D. R., Giovannoni, S. J., White, D. C., Champine, J. E., Philips, E. J. P., Gorby, Y. A., Goodwin, S. (1993) Geobacter metallireducens gen. nov. sp., a Microorganism Capable of Coupling the Complete Oxidation of Organic Compounds to the Reduction of Iron and Other Metals. Arch Microbiology 159: 336-344.

Muyzer G., Ellen C. De Wall and Uitterlinden A. G. (1993) Profiling of Complex Microbial Population by Denaturing Gradient Gel Electrophoresis Analysis of Polymerase Chain Reaction-Amplified Genes Coding for 16 rRNA. Applied and Environmental Microbiology 59: 695-700.

Neefs, J.M., Van de Peer, Y., Hendriks, L., and De Wacther (1990) R. Nucleic Acids Research 18: 2237-2317.

Nevin, K. P.,Lovley, D. R. (2000) Lack of Production of Electron-Shuttling Compounds or Solubilization of Fe(III) during Reduction of Insoluble Fe(III) Oxide by Geobacter metallireducens. Applied and Environmental Microbiology 66: 2248-2251.

Niggemyer, A., Spring., S, Stackebrandt, E., Rosenzweig, R. F. (2001) Isolation and characterization of a Novel As(V)-Reducing Bacterium: Implication for Arsenic Mobilization and the Genus Desulfitobacterium. Applied and Environmental Microbiology 67: 5568-5580.

Nonaka, H., Keresztes, G., Shinoda, Y., Ikenaga, Y., Abe, M., Naito, K., Inatomi, K., Furukawa, K., Inui, M., Yukawa, H. (2006) Complete Genome Sequence of the Dehalorespiring Bacterium Desulfitobacterium hafniense Y51 and Comparison with Dehalococcoides ethenogenes 195. Journal of Bacteriology 188: 2262-2274.

Quan Z.X, Bae J.W., Rhee S.K., Cho, Y.G., Lee, S.T. (2004) Toxicity and degradation of metal-complexed cyanide by a bacterial consortium under sulfate-reducing conditions. Biotechnology Letters 26: 1007-1011.

Sani R.K., Peyton B.M., Brown L.T. (2001) Copper-Induced Inhibition of Growth of Desulfovibrio desulfuricans G20: Assessment of Its Toxicity and Correlation with Those of Zinc and Lead. Applied and Environ Microbiology 67: 4765-4772.

Scherer, M. M., Richter, S., Valentine, R. L., and Alvarez, P. J. J. (2000) Chemistry and Microbiology of Permeable Reactive Barriers for In Situ Groundwater Clean up. Critical Reviews in Environmental Science and Technology 30: 363-411.

Schwiertz , A. , Hold G. L., Duncan S. H., Gruhl B., Collins M. D., Lawson P. A., Flint H. J., Blaut M. (2002) Anaerostipes caccae gen. nov., sp. nov., a New Saccharolytic, Acetate-utilising, Butyrate-producing Bacterium from Human Feces. Systematic and Applied Microbiology 25: 46-51.

Smedley, P. L. and Kinniburgh, D. G. (2002) A Review of the Source, Behavior and Distribution of Arsenic in Natural Waters. Applied Geochemistry 17: 517-568.

Stolz, J.F., Basu, P., Santini, J.M., and Oremland, R.S. (2006) Selenium and Arsenic in Microbial Metabolism. Annual Reviews Microbiology. 60: 107-130. 
Stolz, J.F., Perera, E., Kilonzo, B., Kail, B., Crable, B., Fisher, E., Ranganathan, M., Wormer, L., and Basu, P. (2007) Biotransformation of 3-nitro-4-hydroxybenzene arsonic acid and release of inorganic arsenic by Clostridium species. Environmental Science and Technology. 41: 818-823.

Suyama, A., R. Iwakiri, K. Kai, T. Tokunaga, N. Sera, and K. Furukawa (2001) Isolation and charaterization of Desulfitobacterium sp. Strain Y51 capable of efficient dehalogenation of tetrachloroethene and poly- chloroethanes. Bioscience Biotechnology Biochemistry 65: $1474-1481$

Utkin, I., C. Woese, and J. Wiegel (1994) Isolation and characterization of Desulfitobacterium dehalogenans gen. nov. sp. Nov., an anaerobic bacterium which reductively dechlorinates chlorophenolic compounds. International Journal of Systematic Bacteriology. 44: 612619. 